\title{
Do Parents Rear their Children as they were Reared Themselves? Intergenerational Transmission of Parental Styles (Warmth and Control) and Possible Mediation by Personality Traits
}

\author{
Mio Tanaka ${ }^{1}$, Toshinori Kitamura ${ }^{*}, 1, \mathrm{Zi} \mathrm{Chen}^{2}$, Mikihiko Murakami ${ }^{3}$ and Yoshitaka Goto ${ }^{3}$ \\ ${ }^{I}$ Department of Clinical Behavioural Sciences (Psychological Medicine), Kumamoto University Graduate School of \\ Medical Sciences, Kumamoto, Japan \\ ${ }^{2}$ Research Center of Applied Psychology, Cheng Du Medical College, Cheng Du, China \\ ${ }^{3}$ Kumamoto Paediatric Association, Japan
}

\begin{abstract}
In order to examine the intergenerational transmission of reported parenting styles (warmth and control) and their mediation by personality traits, a cross-sectional questionnaire study was conducted of 396 fathers and 733 mothers of children from less tan 1 to 10 years of age. The participants used the Parental Bonding Instrument (PBI) to measure their own and their partner's current rearing styles as well as to assess their perception of the parenting they had received before age 16. Parents' personality traits were measured using the Temperament and Character Inventory (TCI). in both fathers and mothers, the correlation of the grandparents' perceived parenting styles were correlated with the current parenting styles reported by parents themselves greater than with the current parenting styles reported by spouse. Thus, we speculated the shared observer bias and used the spouse-report for further analyses. In the fathers, (1) paternal Care was correlated with the grandmothers' Care and grandparents' low Overprotection; and paternal Overprotection was correlated with the grandfathers' Overprotection; (2) Novelty Seeking was correlated with the grandparents' Overprotection and low Care; Harm Avoidance was correlated with the grandparents' Overprotection; Reward Dependence, Self-directedness, and Co-operativeness were correlated with the grandparents' Care and low Overprotection; and Persistence was correlated with the grandparents' Care; (3) Overprotection was correlated with Harm Avoidance and low Self-directedness. In the mothers, (1) maternal Care was correlated with the grandmothers' Care; (2) Novelty Seeking was correlated with the grandmothers' low Care; Harm Avoidance was correlated with the grandfathers' low Care and the grandparents' Overprotection; Reward Dependence, Self-directedness, and Co-operativeness were correlated with the grandparents' Care and low Overprotection; and Self-transcendence was correlated with the grandfathers' Care; (3) maternal Care was correlated with Reward Dependence, Persistence, and Co-operativeness; and maternal Overprotection was correlated with low Self-directedness. The transmission of Overprotection of fathers and Care of mothers from the grandparent generations was found to be mediated by personality traits.
\end{abstract}

\section{INTRODUCTION}

Parenting styles (warmth and control) have been viewed as very important in understanding the mental health of children and parents as well as childhood personality development [1-12] and the onset of mental illnesses in adulthood [13-19]. Parents' rearing behaviours are similar to those experienced by their own parents when they were children. For example, transmission of corporal punishment is often reported to occur between two generations [20]. Parents raise their children as they themselves were raised [21]. An aim of this study is whether and how much parenting styles are similar from one generation to another.

The intergenerational transmission of parenting styles may occur through social learning [22]. When grown up and starting to raise their own children, people may do so through the experiences of being raised while their own

*Address correspondence to this author at the Department of Clinical Behavioural Sciences (Psychological Medicine), Kumamoto University Graduate School of Medical Sciences, Kumamoto, Japan;

Tel/Fax: 081-96-373-5181; E-mail: kitamura@kumamoto-u.ac.jp childhood [22]. Alternatively the intergenerational transmission of parenting styles may be mediated by third variables. A candidate of such mediators is personality. Personality development is believed to be partly hereditary and partly environmentally determined [23-25]. Early external influences include parental separation [26, 27], perceived rearing [1, 28-32], child abuse [26, 27], and others. Thus the perceived parenting styles may lead to the personality development. On the other hand, parental warmth was predicted by low parental neuroticism and parental protectiveness was predicted by high parental neuroticism [33]. Thus the parental personality may lead to how parents behave towards the child.

Such consideration suggests that the link between the perceived parenting that children experienced during childhood and the children's own parenting styles when they themselves become parents is mediated by their personality. We hypothesise that there are qualitative links between parenting styles and personality traits that determines such mediation. For example, if parents treat their children with affection, their children will develop personality characterised with affection and compassion. These children 
may be warm not only towards adult acquaintances but also, when they become parents, towards their child. If parents respect autonomy of their children in everyday life, the children learn the importance of autonomy. Such children will value the life goal and independence of adult acquaintances but also, when they become parents, of their child. Therefore it may be a specific aspect of human value that is transmitted from one generation to another through mediation of personality development.

This report investigates the mode of transmission of parenting styles and the possible mediation by the parents' personality traits among a community family population. A group of Japanese parents who attended local paediatric clinics were asked to rate their own experiences being raised as children, their partners' parenting style towards the child, and their own personality.

We speculated that parenting styles with care and affection would be mediated by personality with compassion and empathy whereas parenting styles with intrusiveness towards child would be mediated by personality with excessive worry, pessimism, and fear in unfamiliar situations.

We consider that the association between parenting styles and personality is basically similar in different cultural background. However, because of paucity of the literature in this filed reported from Asian countries, we think it of value to examine this issue using instruments developed in Western countries so that transcultural comparison may become possible.

\section{METHOD}

\section{Participants}

We sent questionnaires to paediatric clinics in Kumamoto Prefecture. Paediatricians handed the questionnaire to the parent(s) of each child who visited the clinic. The parents were asked to enter the study and, if they agreed to do so, they were given another questionnaire so that each partner had a copy. The fathers and mothers were asked to fill out the questionnaire independently. The total number of families who participated in the questionnaire survey was 759. However, only 396 fathers and 733 mothers returned the questionnaires in that the sufficient number of the items used for the present analyses was filled in. The number of families in which both father and mother returned the questionnaire was 370. The numbers of families in which only father and only mother returned the questionnaire were 26 and 363, respectively. The father's age was significantly $(p<.05)$ greater among the families in which only father returned the questionnaire (mean $=37.8, \mathrm{SD}=5.8$ ) than among the families in which both parents returned the questionnaire (mean $=35.2, \mathrm{SD}=6.1$ ). However, the mother's age did not differ between the families in which only mother returned the questionnaire and those in which both parents returned the questionnaire. As expected, a portion of the families in which only one parent returned the questionnaire were those of separated or divorcees $(9 \%$ separated and $9 \%$ divorced of the families in which only father and mother returned the questionnaire).

The mean (SD) age of the fathers was 35.4 (6.1) years and the mean (SD) age of the mothers was 33.3 (5.5). Most of the parents were married or cohabiting. Only 9 fathers and 13 mothers were separated, 2 fathers and 19 mothers were divorced, and 2 mothers were widowed. The mean age (SD) of the children was 3.6 (2.7) years. There were 390 boys $(51.4 \%)$ and 346 girls $(45.6 \%)$. The gender was unknown for the remaining 23 children $(3.0 \%)$.

It may be of note that Kumamoto Prefecture is located in Kyushu, the southernmost of the four major islands in Japan. Its population is about $1,800,000$. Most of clinics are in the Kumamoto, the capital of Kumamoto Prefecture. As in other areas in Japan, healthcare services are provided by the government. Payment of medical services is offered through a universal health care insurance system. Patients pay about $30 \%$ of the free while the remaining fee is covered by the insurance. Patients (parents in the case of child patients) are free to select physicians and hospitals of their own choice. Thus, paediatric clinics function as if GP for children.

\section{Measurements}

Grandparents' and parents' parenting style: As a measure of perceived or reported parenting style we used the Parental Bonding Instrument (PBI) [34]. The PBI was originally developed as a measure to assess retrospectively how an individual perceived their father's and mother's parenting (separately) before age 16. In this study, we used it as originally indicated for assessing the grandparents' (i.e., the parents' parents) parenting style as rated by the parents. The PBI was also used as a measure of each parent's parenting style as rated by him/herself and his or her spouse. Parker [35] postulated two subscales: Care and Overprotection. Care consists of 12 items (with a four-point scale) related to a parenting style that may range from coldness, indifference, and neglect, to affection, emotional warmth, empathy, and reciprocity. This subscale includes items like "spoke to me with a warm and friendly voice", and "frequently smiled at me". Overprotection consists of 13 items (with a 4-point scale) ranging from parental control and overprotection, intrusion, and infantilization, to parental allowance, independence, and the development of autonomy. This subscale includes items like "invaded my privacy", and "tried to make me dependent on him/her". The PBI has been demonstrated to have acceptable validity [35]. The Japanese version of this scale was used [36]. The factor structure of the PBI among a Japanese population is virtually the same as that originally reported [37].

For assessing the parents' current parenting style, we used the PBI but rephrased sentence tenses into the present, a modification proposed by Parker and colleagues [38]. We asked parents to rate their own parenting style towards the child who consulted the clinic. In addition, we asked each spouse to rate the other spouse's parenting styles towards this child. Thus, the mother was asked to rate the father's parenting style while the father was asked to rate the mother's parenting style. This was to see whether we should avoid the possible biases of self-perception of one's own parenting style influencing the recall of childhood experiences, or vice versa. Missing PBI values were substituted with the mean of the item only for those cases with fewer than 20 items ( $80 \%$ of the whole items) missing.

Parents personality: As a measure of parents' personality we used the Temperament and Character 
Inventory (TCI) [39]. The TCI measures four temperament dimensions (Novelty Seeking, Harm Avoidance, Reward Dependence, and Persistence) and three character dimensions (Self-directedness, Cooperativeness, and Selftranscendence).

According to the theory of Cloninger, Przybeck, Svrakic and Wetzel [39], temperament, largely determined by genetics, configures automatic behaviour responses. Novelty Seeking indicates a heritable bias in the activation and initiation of behaviours. Individuals high in Novelty-Seeking are characterised by exhilaration in response to novel stimuli, intuitive decision-making, and active avoidance of rules or orders. Harm Avoidance indicates a heritable bias for inhibition and cessation of behaviours. Individuals high in Harm-Avoidance are characterised by worry, pessimism, easy fatigue, tenseness in unfamiliar situations, and shyness with strangers. Reward Dependence indicates a heritable bias for maintenance of ongoing behaviours. Individuals high in Reward Dependence are characterised by being sentimental, affectionate, and dependent upon the approval of others. Persistence indicates perseverance of behaviour despite frustration and fatigue. Individuals high in Persistence are characterised by being industrious, determined, and tenacious. Character is viewed as individual differences in higher cognitive processes regulating the processes of sensory perception and emotion provoked by temperament, leading to the development of a mature concept of the self in the personal, social, and spiritual arenas. Self-Directedness indicates identification with the autonomous self and the confidence to deal with any situation in accordance with one's goals and values. Individuals high in Self-directedness are characterised by high self-esteem, responsibility, and the ability to pursue a purpose. Co-operativeness indicates the extent to which individuals view other people as a part of the self. Individuals high in Cooperativeness are characterised by social tolerance, empathy, helpfulness, and compassion. Self-transcendence indicates identification with a unity of all things in the world. Individuals high in Self-Transcendence are characterised by being fulfilled, serene, intuitive, creative, and spiritual. Because the 125 -item version of the adult TCI includes as few as five items for Persistence we added another five items to this dimension.

The original true-false response scale was modified into a four-point scale, which has better internal consistency among Japanese populations [40]; the four-point scale ranges from 0 ("strongly disagree") to 3 ("strongly agree"). There are some reverse items. The validity of the temperament subscales of the TCI was confirmed by Cloninger [41]. Reliability and factor validity of the Japanese version of the TCI were reported [40, 42]. In this study we asked each parent to assess his or her own personality. Missing TCI values were substituted with the mean of the item only for those cases with less than 104 items ( $80 \%$ of the whole items) missing.

\section{Procedure}

Paediatricians distributed the set of questionnaires to the father or mother in each paediatric clinic. A question in the survey requested parents' voluntary participation, and we asked parents to solicit their spouse's cooperation as well. They were requested to return the questionnaire directly to the researcher using a stamp added envelope. Anonymity was confirmed. However, in order to match questionnaires arriving from members of the same household, a serial number was added to the face sheet.

This research project was approved by the Ethical Committee of Kumamoto University Graduate School of Medical Sciences.

\section{Statistical Analyses}

All the statistical analyses were conducted using the Statistical Package for Social Science (SPSS) version 12.0.

\section{RESULTS}

\section{Preliminary Analyses}

The means and SDs of all the variables used in this study are shown in Table 1. There were virtually no differences between parents with boys and those parents with girls in terms of these variables except for a few variables. Fathers' Self-transcendence was significantly $(p<.05)$ higher for fathers with boys (mean = $17.4, \mathrm{SD}=6.4)$ than fathers with girls (mean $=16.1, \mathrm{SD}=5.9$ ). Mothers' own-report of Care was significantly $(p<.05)$ higher for mothers with boys (mean $=29.3, \mathrm{SD}=3.5$ ) than fathers with girls (mean $=28.5, \mathrm{SD}=4.2)$. Mothers' Overprotection rated by the spouse was significantly $(p<.01)$ higher for mothers with boys $($ mean $=12.9, \mathrm{SD}=5.2)$ than fathers with girls (mean $=11.4, \mathrm{SD}=4.9$ ). However, the magnitude of these differences was all small.

\section{Correlations Between Grandparents' Perceived And Parents' Reported Parenting Styles}

A first assumption of this study was that perceived/reported parenting styles would be similar between two consecutive generations. Significant correlations were indeed found between some parents' and grandparents' parenting styles. For instance, as expected, in both the Care and Overprotection scores, parents' ownreports were moderately correlated with their recall of their grandparents (Table 2). Parental own-report of Care was moderately and inversely correlated with the parental recall of their grandparents Overprotection. Fathers' own-report of Overprotection was also inversely correlated with the grandfathers' Care.

A purpose of this study was to examine a possible shared observer bias. Thus, we calculated the correlation between the grandparents parenting styles and the parent's current parenting styles reported by the spouse in the families in which both parents returned the questionnaire. This is because a portion of the families in which only one parent returned the questionnaire included divorcees or separated and thus might lead to distortion of data. Most of the correlations found between grandparents' perceived parenting styles and parents' own report of parenting styles disappear when the parental style was reported by the spouse. Grandmothers' Care remained to be significantly correlated with the spouse-reports of fathers' and mothers' Care and grandfathers' Overprotection remained to be significantly correlated with the spouse-report of fathers' Overprotection.

These findings suggest similarity of Care between grandparents and parents as well as Overprotection between grandfathers and fathers. 
Table 1. Means and SDs of Perceived/Reported Parental Styles of Grandparents and Parents and Parents' Personality Traits

\begin{tabular}{|c|c|c|c|c|c|}
\hline Variables & $\mathbf{n}$ & $\mathbf{M}$ & SD & Possible Range of Score & Cronbach's Alpha Coefficient \\
\hline \multicolumn{6}{|l|}{ Paternal Grandparents PBI } \\
\hline Grandmother's Care & 375 & 26.9 & 5.8 & $0-36$ & .87 \\
\hline Grandfather's Overprotection & 372 & 12.4 & 6.4 & $0-39$ & .89 \\
\hline \multicolumn{6}{|l|}{ Maternal Grandparents PBI } \\
\hline Grandfather's Care & 717 & 23.1 & 7.5 & $0-36$ & .92 \\
\hline Grandmother's Care & 720 & 26.9 & 6.7 & $0-36$ & .86 \\
\hline Grandfather's Overprotection & 717 & 11.3 & 6.4 & $0-39$ & .92 \\
\hline Care spouse-report & 364 & 28.8 & 5.0 & $0-36$ & .85 \\
\hline Overprotection own-report & 385 & 12.4 & 4.3 & $0-39$ & .64 \\
\hline Overprotection spouse-report & 364 & 11.0 & 4.6 & $0-39$ & .62 \\
\hline \multicolumn{6}{|l|}{ Maternal PBI } \\
\hline Care own-report & 719 & 28.7 & 4.1 & $0-36$ & .78 \\
\hline Care spouse-report & 355 & 30.2 & 4.3 & $0-36$ & .80 \\
\hline Overprotection own-report & 719 & 12.7 & 4.3 & $0-39$ & .66 \\
\hline Overprotection spouse-report & 355 & 12.3 & 5.2 & $0-39$ & .75 \\
\hline Self-directedness & 378 & 43.1 & 9.0 & $0-75$ & .85 \\
\hline Co-operativeness & 378 & 46.4 & 7.0 & $0-75$ & .78 \\
\hline Self-transcendence & 378 & 16.7 & 6.2 & $0-45$ & .81 \\
\hline \multicolumn{6}{|l|}{ Maternal TCI } \\
\hline Novelty Seeking & 722 & 23.5 & 6.4 & $0-57$ & .77 \\
\hline Harm Avoidance & 722 & 33.2 & 7.6 & $0-60$ & .85 \\
\hline Reward Dependence & 722 & 31.3 & 5.1 & $0-48$ & .69 \\
\hline Persistence & 722 & 16.5 & 3.3 & $0-30$ & .60 \\
\hline Self-directedness & 722 & 41.4 & 8.7 & $0-75$ & .84 \\
\hline Co-operativeness & 722 & 49.5 & 6.2 & $0-75$ & .74 \\
\hline Self-transcendence & 722 & 16.7 & 6.3 & $0-45$ & .82 \\
\hline
\end{tabular}

\section{Correlations Between Grandparents' Perceived Parenting Style and Parents' Personality}

Grandparents' perceived parenting styles were correlated with some of the parents' personality traits (Table 3 ).

Thus, for both fathers and mothers, grandparents' perceived Care scores were correlated with parents' Reward dependence, Self-directedness and Co-operativeness scores. Grandparents' perceived Overprotection scores were correlated positively with parents' Harm Avoidance scores and negatively with parents' Reward Dependence, Selfdirectedness and Co-operativeness scores. For both fathers and mothers, grandmothers' perceived Care scores were negatively correlated with Novelty Seeking scores. 
Table 2. Correlation Between Parents' Reported Parenting Styles and Grandparents' Perceived Parenting Styles

\begin{tabular}{|c|c|c|c|c|}
\hline \multirow{2}{*}{ Grandparents' Parenting Styles } & \multicolumn{2}{|c|}{ Father's Parenting Styles } & \multicolumn{2}{|c|}{ Mother's Parenting Styles } \\
\hline & Care & Overprotection & Care & Overprotection \\
\hline \multicolumn{5}{|l|}{ Care } \\
\hline Grandfather & $\begin{array}{l}.28 * * *(364) \\
.07(343)\end{array}$ & $\begin{array}{l}-.12 *(364) \\
-.05(343)\end{array}$ & $\begin{array}{l}.15 * * *(703) \\
.06(351)\end{array}$ & $\begin{array}{l}.00(703) \\
-.10(351)\end{array}$ \\
\hline Grandmother & $\begin{array}{l}. \mathbf{3 4} * * *(366) \\
. \mathbf{1 7} * *(347)\end{array}$ & $\begin{array}{l}-.08(366) \\
-.04(347)\end{array}$ & $\begin{array}{l}. \mathbf{2 0} * * *(706) \\
.16 * *(347)\end{array}$ & $\begin{array}{l}.02(706) \\
-.08(347)\end{array}$ \\
\hline \multicolumn{5}{|l|}{ Overprotection } \\
\hline Grandfather & $\begin{array}{l}-.22 * * *(346) \\
-.18 * *(343)\end{array}$ & $\begin{array}{l}. \mathbf{2 0} * * *(364) \\
.17 * *(343)\end{array}$ & $\begin{array}{l}-.11 * *(703) \\
-.03(351)\end{array}$ & $\begin{array}{l}.13 * * *(703) \\
.06(351)\end{array}$ \\
\hline Grandmother & $\begin{array}{l}-.20 * *(366) \\
-.14 *(347)\end{array}$ & $\begin{array}{l}.22 * * *(366) \\
.09(347)\end{array}$ & $\begin{array}{l}-.12 * *(706) \\
-.08(347)\end{array}$ & $\begin{array}{l}.18 * * *(706) \\
.10(347)\end{array}$ \\
\hline
\end{tabular}

Upper figure of each cell reflects correlation with own-report of each parenting style, lower figure reflects correlation with spouse-report of each parenting style $* p<.05, * * p<.01$, $* * * p<.001$.

For fathers only, grandparents' perceived low Care and Overprotection scores were correlated with Novelty Seeking. Grandparents' perceived Care scores were correlated with Persistence.

Only For mothers, grandmothers' perceived Care scores were correlated with self-transcendence and negatively with Harm Avoidance.

\section{Correlations Between the Parenting Styles and Personality}

A second assumption of this study was that individuals' reported parenting styles were determined by their own personalities. Thus, we correlated parents' personalities with their reported parenting styles (Table 4). Many of the ownreport of parenting styles were correlated with the parental personality. Thus parental reports of Care were correlated with Reward Dependence, Persistence, Self-directedness, and Co-operativeness and was inversely correlated with Novelty Seeking and Harm Avoidance. Parental report of Overprotection was correlated with Harm Avoidance and was inversely correlated with Reward Dependence, Self- directedness, and Co-operativeness. In addition, Fathers' own-report of Overprotection was correlated with Novelty Seeking and mothers' own-report of Overprotection was correlated with Persistence. However, these findings lost significance for the spouse-report of parenting styles. Only a few correlations remained as significant. Thus, the spousereport of parental Overprotection was inversely correlated with Self-directedness. The spouse-report of paternal Overprotection was correlated with Harm Avoidance. The souse-report of maternal Care was correlated with Reward Dependence, Persistence, and Co-operativeness.

\section{Meditation of Parents' Personality on the Effects of and Grandparents' Parenting Styles on Parents' Parenting Styles}

While considering mediation of parental personality on the effects of the past rearing on the parents' reported current parenting styles, we used the spouse-report as the measure of the current parental styles because the parental own reports may risk a shared observer bias. In deed, the parental styles reported by parents themselves were correlated with the grandparents' parenting styles they perceived as a child

Table 3. Correlation Between Parents' Personality and Grandparents' Parenting Styles

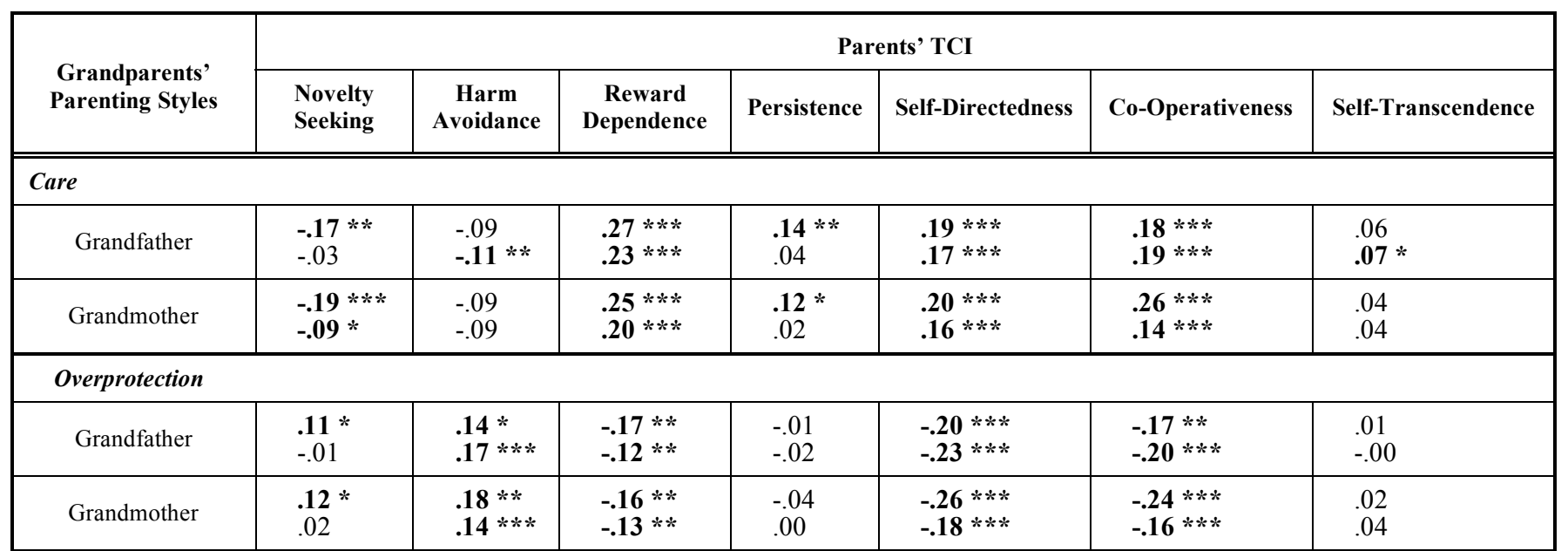

Upper figure of each cell reflects fathers ( $n=359$ for grand fathers and $n=363$ for grandmothers), lower figure reflects mothers ( $n=709$ for grandfathers and $n=712$ for grandmothers).

$* p<.05, * * p<.01, * * * p<.001$ 
Table 4. Correlation between Parents' Personality and their Own Parenting Styles

\begin{tabular}{|c|c|c|c|c|}
\hline \multirow{2}{*}{ Parents' TCI } & \multicolumn{2}{|c|}{ Father's Parenting Styles } & \multicolumn{2}{|c|}{ Mother's Parenting Styles } \\
\hline & Care & Overprotection & Care & Overprotection \\
\hline Novelty Seeking & $\begin{array}{l}-.15 * *(369) \\
-.05(348)\end{array}$ & $\begin{array}{l}.15 * *(369) \\
-.02(348) \\
\end{array}$ & $\begin{array}{l}-.16 * * *(708) \\
.11(352)\end{array}$ & $\begin{array}{l}.06(708) \\
.05(352)\end{array}$ \\
\hline Harm Avoidance & $\begin{array}{l}-.18 * * *(369) \\
-.06(348)\end{array}$ & $\begin{array}{l}.25 * * *(369) \\
.14 *(348)\end{array}$ & $\begin{array}{l}-.22 * * *(708) \\
-.02(352)\end{array}$ & $\begin{array}{l}.21 * * *(708) \\
.10(352)\end{array}$ \\
\hline Reward Dependence & $\begin{array}{l}.22 * * *(369) \\
.04(348)\end{array}$ & $\begin{array}{l}-.14 * *(369) \\
.00(348)\end{array}$ & $\begin{array}{l}. \mathbf{2 1} * * *(708) \\
. \mathbf{1 1} *(352)\end{array}$ & $\begin{array}{l}-.09 *(708) \\
.02(352)\end{array}$ \\
\hline Persistence & $\begin{array}{l}.14 * *(369) \\
.12 *(348)\end{array}$ & $\begin{array}{l}-.05(369) \\
-.00(348)\end{array}$ & $\begin{array}{l}. \mathbf{1 3} * *(708) \\
.14 *(352)\end{array}$ & $\begin{array}{l}-.09 *(708) \\
-.06(352)\end{array}$ \\
\hline Self-directedness & $\begin{array}{l}.28 * * *(369) \\
.09(348)\end{array}$ & $\begin{array}{l}\mathbf{- . 3 2} * * *(369) \\
\mathbf{- . 1 4} * *(348)\end{array}$ & $\begin{array}{l}.37 * * *(708) \\
.10(352)\end{array}$ & $\begin{array}{l}-.25 * * *(708) \\
-.11 *(352)\end{array}$ \\
\hline Co-operativeness & $\begin{array}{l}.29 * * *(369) \\
.10(348)\end{array}$ & $\begin{array}{l}-.23 * * *(369) \\
-.09(348)\end{array}$ & $\begin{array}{l}. \mathbf{3 0} * * *(708) \\
. \mathbf{1 4} * *(352)\end{array}$ & $\begin{array}{l}-.23 * * *(708) \\
-.07(352)\end{array}$ \\
\hline Self-transcendence & $\begin{array}{l}-.01(369) \\
.08(348)\end{array}$ & $\begin{array}{l}.05(369) \\
-.02(348)\end{array}$ & $\begin{array}{l}.05(708) \\
.10(352)\end{array}$ & $\begin{array}{l}-.03(708) \\
-.04(352)\end{array}$ \\
\hline
\end{tabular}

Upper figure reflects correlation with own-report of each parenting style, lower figure reflects correlation with spouse-report of each parenting style $* p<.05, * * p<.01, * * * p<$ .001 .

much greater than the parenting styles reported by their spouses were. Of course, it may be interpreted that the spousal report of the parental styles of a parent is less accurate and the parent him/herself is a most appropriate rater of his/her own attitudes. However, we took a conservative stance in this study. Findings observed through the spousal reports may be less biased if not accurate.

The findings reported here indicate that while fathers' Care was correlated with some of the parenting they perceived as a child, it was not correlated with any of their personality trait. Mothers' Overprotection was not correlated with any of the past perceived parenting as a child. Thus we did not consider possible mediation of the personality on the links between the past perceived parenting as a child and the current parental Care and maternal Overprotection [43].

On the other hand, (1) fathers' Overprotection was correlated with grandfathers' perceived Overprotection, (2) fathers' Harm Avoidance and Self-directedness were correlated with grandfathers' perceived Overprotection, and (3) fathers' Overprotection was correlated with their Harm Avoidance and Self-directedness. For mothers, (1) Care was correlated with grandmothers' perceived Care, (2) the mothers' Reward Dependence, Persistence, and Cooperativeness were correlated with grandmothers' perceived Care, and (3) Care was correlated with the mothers' Reward Dependence, Persistence, and Co-operativeness.

We then conducted a series of hierarchical multiple regression analyses to examine whether the effects of the grandparents' perceived parenting styles on parents' own parenting styles (reported by the spouse) was mediated completely or partially by the parental personality. First, fathers' perceived Overprotection was regressed on (1) paternal age, (2) paternal Harm Avoidance and Selfdirectedness, and (3) the four types of grandparents' perceived parenting styles, consecutively. The step $2\left(\mathrm{R}^{2}\right.$ increase $=.023, p<.05$ ) contributed to the increase of $\mathrm{R}^{2}$ of the fathers' Overprotection but step 3 failed to do. The overall adjusted $\mathrm{R}^{2}$ of the regression formula was .033 .
Second, mothers' Care was regressed on (1) maternal age, (2) maternal Reward Dependence, Persistence, and Cooperativeness, and (3) the four types of grandparents' perceived parenting styles, consecutively. The step $2\left(\mathrm{R}^{2}\right.$ increase $=.031, p<.05)$ contributed to the increase of $\mathrm{R}^{2}$ of the mothers' Care but step 3 failed to do so. The overall adjusted $\mathrm{R}^{2}$ for this regression formula was .058 . Thus, in fathers' Overprotection and mothers' Care, the mediation of the maternal personality on the effects of grandmothers' perceived parenting styles on the parental styles of the parents seemed to be complete.

\section{DISCUSSION}

Bias is an important issue to consider with studies that are based on participants' retrospective recall, particularly when the memories involve subjects' personal experiences or attitudes towards important others. The use of a widely employed measure such as the PBI does not obviate the need to examine this issue carefully. Parker [17] compared PBI ratings of mothers made by both the mothers themselves and by their children. He found that the correlations between these two ratings were .44 for Care and .55 for Overprotection. For a Japanese population Kitamura and Suzuki [36] used a family unit of father, mother, and child. The PBI assessment of one or both parents differed among the three members of the family.

In this study there were two raters: fathers (husbands) and mothers (wives). We are not aware which raters' assessments most closely reflected the actual parenting behaviours. To the best of our knowledge, there have been no studies comparing the results of direct observation of parenting behaviours with those of self-reports. We believe it is reasonable to speculate, however, that each parent, whether father or mother, would tend to rate similarly their own parenting style and their perception of their parents' parenting style. Indeed, in this study significance of most of the correlations found between grandparents' perceived parenting styles and fathers' and mothers' own report of parenting styles disappeared when the former was correlated 
with the spousal report of the parenting styles. Hence, we decided to use the spousal ratings rather than the parents' own ratings as the measure of parenting style. Future studies should employ direct observation of parenting behaviour to provide a more definitive conclusion about this issue. Debate of the accuracy of parental report of parent-child relationship dates back even to 1940s [44].

The present study partially confirmed that parenting styles are transmitted between generations. However, gender differences were found: Overprotection is transmitted from grandfathers to fathers while Care is transmitted from grandmothers to mothers. While there are genetic contributions to parenting styles [45], little has been reported regarding the extent of such transmission. Our results, though not conclusive, encourage further validation studies. Studies on modes of such transmission and other possible mediators may cast more light on the influence of gender differences on intergenerational transmission.

The link between parental personality and parenting styles was again gender specific. Thus, mothers' Care was predicted by Reward Dependence, Persistence, and Cooperativeness. Parental Overprotection was predicted by low Self-directedness and fathers' Overprotection was predicted by high Harm Avoidance. The characteristics measured by the TCI reflect one's interactivity with other people and the environment. Individuals with a high degree of Cooperativeness sympathise strongly with others and are described as empathic, tolerant, compassionate, supportive, fair, and principled [39, p. 26]. Because parenting behaviours are a means for parents to communicate with and nurture their child, personality traits attributed to Co-operativeness may be important for good parenting styles. Parents high in Reward Dependence are more likely to be affectionate to the child. Parents high in Persistence are industrious even under stressful situations. These traits may enhance warm parenting styles derived from Co-operativeness. Selfdirectedness, on the other hand, describes people who are mature, self-sufficient, goal-oriented, and well integrated. Parents with these qualities may respect their children's autonomy, while parents low in Self-directedness may overprotect them. Parents with a high degree of Harm Avoidance may be more likely to be fearful in unfamiliar situations. Thus, when raising a child, they may be more likely to give excessive early warning to the child and to be overprotective.

Some of parental personality traits were predicted by grandparents' perceived parenting styles. Thus, temperament and character dimensions related to affection and autonomy -- Reward Dependence, Self-directedness, and Cooperativeness --- were predicted by grandparents' perceived high Care and low Overprotection. Traits related to fear and pessimism --- Harm Avoidance --- was predicted by grandparents' perceived Overprotection and low Care.

We hypothesised that the link in parenting styles between two generations would be mediated by the parents' personalities. This was only suggested for the fathers' Overprotection and mothers' Care. Associations of Overprotection between grandfathers and fathers and of Care between grandmothers and mothers observed in bivariate analyses lost its significance when controlled for personality traits related to affection and those traits related to fear suggesting such personality traits mediate the parenting quality separately. This note is, however, only tentative and needs further replication studies.

We should comment on the limitations of this study. First, given that it is cross-sectional in nature we cannot distinguish the effects of parenting styles on children's personality from those of children's personality on their parents' attitudes toward them. We relied on parents' memories for assessing their parents' parenting styles. This method is subject to recall bias despite some evidence to support its reliability [46-49]. Thus, for example, children may be autonomous (high Self-directedness) and compassionate (high Co-operativeness) because the parents treated them with affection (high Care) and respect for autonomy (low Overprotection). Alternatively, parents treat them with affection (high Care) and respect for autonomy (low Overprotection) because the child is autonomous (high Self-directedness) and compassionate (high Cooperativeness). Our sample was a convenient one and it is not representative of the Japanese population.

Another weakness of the findings is the portion of variance of the current parenting styles explained by the parental personality and the perceived rearing the parents experienced as a chid was very small. This means that there are many variables other than the parental personality and the perceived parental styles during their own childhood that contribute the parents' current parenting styles.

It should be remembered that parenting behaviour is multiply determined. What determines parenting styles are not limited to personality and perceived parenting parents themselves experienced as children. They may include parent's and child's characteristics and contextual factors in which the child is raised [50]. Moreover, the effects such characterises on the parenting styles may be addictive or cumulative. They may be mediated or moderated by other variables. Alternatively multiple characteristics may predict the parenting styles through predicting each other over the course of time. Therefore the result of the present study should be viewed as just one element of the determinants of parenting styles.

The present study was conducted in a Japanese population. Although it goes beyond the scope of the present study, we should be careful about interpreting the results because there may be intercultural differences. For example, unlike in the Western countries [51-54], Brazilian teenagers with indulgent parents showed equal or higher level of selfesteem than teenagers with authoritative parents [55]. Colombian children's internalizing problems were associated with perceived maternal acceptance [56]. In a Japanese community population [57], adult depressive episodes were predicted by the perceived maternal care as well as maternal overprotection. This is contrary to reports from the Western countries [58]. These findings suggest that the effects of parenting styles on psychological adjustment differ between different cultures. The findings observed in this study should be replicated in a population from different cultures.

Despite several drawbacks, the present study has shown mothers' parenting styles may be transmitted from one generation to another and that this may be mediated by personality traits. 


\section{ACKNOWLEDGEMENTS}

We than the cooperation of the following paediatricians for collecting the data: Tsuneyoshi Egami, M.D., Hisako Fujikawa, M.D., Akio Furuse, M.D., Yoshiko Hattori, M.D., Yogo Haraguchi, M.D., Kaneshige Iribe, M.D., Tsunehiro Kuwahara, M.D., Toshinari Maeda, M.D., Hiroshi Mitsubuchi, M.D., Toru Miyazaki, M.D., Yuji Mizumoto, M.D., Ryozaburo Seguchi, M.D., Yasushi Shimada, M.D., Shigeto Sugino, M.D., Keiichi Taku, M.D., Tekehiko Ueno, M.D., Kyoko Uramoto, M.D., Ken Watanabe, M.D.

\section{CONFLICT OF INTEREST}

We have no conflict of interest.

\section{REFERENCES}

[1] Benhaminsen S, Jorgensen J, Kragh-Hansen L, Pedersen LL. Memories of parental rearing practices and personality features. Acta Psychiatr Scand 1984; 69: 426-34.

[2] Bowlby J. The influence of early environment in the development of neurosis and neurotic character. Int J Psychoanal 1940; 21: 15478.

[3] Fukunishi I, Saito S, Fujito K. Influence of the mother-child relationship on the development of the type A behavior pattern. Child Psychiatry Hum Dev 1992; 22: 213-20.

[4] George C, Main M. Social interaction of young abused children: approach, avoidance, and aggression. Child Dev 1979; 50: 306-18.

[5] Kendler KS, Sham PC, MacLean CJ. The determinants of parenting: an epidemiological, multi-informant, retrospective study. Psychol Med 1997; 27: 549-63.

[6] Koestner R, Zuroff DC, Powers TA. Family origins of adolescent self-criticism and its continuity into adulthood. J Abnorm Psychol 1991; 100: 191-7.

[7] McCrae RR, Costa Jr PT. Recalled parent-child relations and adult personality. J Pers 1988; 56: 417-34.

[8] Mussen P, Harris S, Rutherford E, Keasey CB. Honesty and altruism among preadolescents. Dev Psychol 1970; 3: 169-94.

[9] Nakao K, Takaishi J, Tatsuta K, et al. The influences of family environment on personality traits. Psychiatry Clin Neurosci 2000; 54: 91-5.

[10] Parker G. Parental rearing style: examining for links with personality vulnerability factors for depression. Soc Psychiatry Psychiatr Epidemiol 1993; 28: 97-100.

[11] Perris C, Eisemann M, Ericsson U, Van Knorring L, Perris H. Parental rearing behaviours and personality characteristics of depressed patients. Arch Psychiatry Neurol Sci 1983; 233: 77-88.

[12] Richter J, Eisemann M, Richter G. Temperament, character and perceived parental rearing in healthy adults: two related concepts? Psychopathology 2000; 33: 36-42.

[13] Alnas R, Torgensen S. Parental representation in patients with major depression, anxiety disorder and mixed conditions. Acta Psychiatr Scand 1990; 81: 518-22.

[14] Eriksson M, Steneroth G, Zetterstrom R. Influence of pregnancy and child-rearing on amphetamine-addicted women. Acta Psychiatr Scand 1986; 73: 634-41.

[15] Heider D, Matschinger H, Bernert S, Alonso J, Angermeyer MC, ESMeD/MHEDEA 2000 investigators. Relationship between parental bonding and mood disorder in six European countries. Psychiatry Res 2006; 143: 89-98.

[16] Lieb R, Wittchen H, Hoefler M, Fuetsch M, Stein M, Merikangas KR. Parental psychopathology, parental styles, and the risk of social phobia in offspring: a prospective-longitudinal community study. Arch Gen Psychiatry 2000; 57: 859-66.

[17] Parder G. Parental representations of patients with anxiety neurosis. Acta Psychiatr Scand 1981; 63: 33-6.

[18] Russell JD, Kopec-Schrader E, Rey JM, Beumont PJV. The parental Bonding Instrument in adolescent patients with anorexia nervosa. Acta Psychiatr Scand 1992; 86: 236-9.

[19] Torgersen S. Developmental differentiation of anxiety and affective neuroses. Acta Psychiatr Scand 1985; 71: 304-10.

[20] Pears KC, Capaldi DM. Intergenerational transmission of abuse: A two-generational prospective study of an at-risk sample. Child Abuse Neglect 2001; 25: 1439-61.
[21] Van IJzendoorn MH. Intergenerational transmission of parenting: A review of studies in nonclinical populations. Dev Rev 1992; 12: 76-99.

[22] Muller RT, Hunter JE, Stollak G. The intergenerational transmission of corporal punishment: A comparison of social learning and temperament models. Child Abuse Neglect 1995; 19: 1323-35.

[23] Buss AH, Plomin R, Willerman L. The inheritance of temperament. J Pers 1973; 41: 513-24.

[24] Goldsmith HH. Genetic influences on personality from infancy to adulthood. Child Dev 1983; 54: 331-55.

[25] Loehlin JC, Willerman L, Horn JM. Human behavior genetics. Ann Rev Psychol 1988; 39: 101-33.

[26] Kendler KS, Kessler RC, Neale MC, Heath AC, Eaves LJ. The prediction of major depression in women: toward an integrated etiologic model. Am J Psychiatry 1993; 150: 1139-48.

[27] Kitamura T, Fujihara S. Understanding personality traits from early life experiences. Psychiatry Clin Neurosci 2003; 57: 323-31.

[28] Kitamura T, Tomoda A, Kijima N, Sakamoto S, Tanaka E, Iwata N. Correlates of retrospective early life experience with personality in young Japanese women. Psychol Rep 2002; 91: 263-74.

[29] Reti IM, Samuels JF, Eaton WW, Bienvenu OJ III, Costa PT Jr, Nestadt G. Influence of parenting on normal personality traits. Psychiatry Res 2002; 111: 55-64.

[30] Ruchkin VV, Eisemann $\mathrm{M}$, Hägglöf $\mathrm{B}$, Cloninger $\mathrm{CR}$ Interrelations between temperament, character, and parental rearing in male delinquent adolescents in Northern Russia. Compr Psychiatry 1998; 39: 225-30.

[31] Ono Y, Yoshimura K, Mizushima H, et al. Environmental and possible genetic contributions to character dimensions of personality. Psychol Rep 1999; 84: 689-96.

[32] Kitamura T, Kishida Y. Early experiences and development of personality: A study of the temperament and character inventory in 4000 university students in Japan. In: Kingler LV, Ed. Trends in lifestyle and health research, Hauppauge: Nova Science Publishers 2005; pp. 1-20.

[33] Kendler KS, Sham PC, MacLean CJ. The determinants of parenting: An epidemiological, multi-informant, retrospective study. Psychol Med 1997; 27: 549-63.

[34] Parker GB, Tupling H, Brown LB. A parental and bonding instrument. Br J Med Psychol 1979; 52: 1-10.

[35] Parker GB. Parental overprotection: A risk factor in psychosocial development. New York: Grune and Stratton 1983.

[36] Kitamura T, Suzuki T. A validation study of Parental Bonding Instrument in Japanese Population. Jpn J Psychiatry Neurol 1993; 47: 29-36

[37] Uji M, Shono M, Kitamura T. Factorial structure of Parental Bonding instrument (PBI) in Japan: a study of cultural, developmental, generational, and sexual influences. Child Psychiatry Hum Dev 2006; 37: 115-32.

[38] Parker GB, Fairley M, Greenvood J, Jurd S, Silove D. Parental representations of schizophrenics and their association with onset and course of schizophrenia. Br J Psychiatry 1982; 141: 573-81.

[39] Cloninger CR, Przybeck TR, Svrakic DM, Wetzel RD. The Temperament and Character Inventory: A Guide to Its Development and Use. St. Louis: Washington University 1994.

[40] Kijima N, Tanaka E, Suzuki N, Higuchi H, Kitamura T. Reliability and validity of the Japanese version of the temperament and character inventory. Psychol Rep 2000; 86: 1050-1058.

[41] Cloninger CR. A systematic method for clinical description and classification of personality variants. A proposal. Arch Gen Psychiatry 1987; 44: 573-88.

[42] Tomita T, Aoyama H, Kitamura T, Sekiguchi C, Murai T, Matsuda T. Factor structure of psychobiological seven-factor model of personality: a model revision. Pers Individ Dif 2000; 29: 709-27.

[43] Baron RM, Kenny DA. The Moderator-Mediator Variable distinction in social psychological research: conceptual, strategic, and statistical considerations. J Pers Soc Psychol 1987; 51: 117382.

[44] Lytton H. Observation studies of parent-child interaction: A methodological review. Child Dev 1971; 42: 651-84.

[45] Kendler K, Baker JH. Genetic influences on measures of the environment: A systematic review. Psychol Med 2007; 37: 615-26.

[46] Brewin CR, Andrews B, Gotlib IH. Psychopathology and early experience: a reappraisal of retrospective reports. Psychol Bull 1993; 113: 82-98. 
[47] Finlay-Jones R, Scott R, Duncan-Jones P, Byrne D, Henderson S. The reliability of reports of early separations. Austr N Z J Psychiatry 1981; 15: 27-31.

[48] Maughan B, Rutter M. Retrospective reporting of childhood adversity: issues in assessing long-term recall. J Pers Dis 1997; 11: 19-33.

[49] Wilhelm K, Niven H, Parker G, Hadzi-Pavlovic D. The stability of the Parental Bonding Instrument over a 20-year period. Psychol Med 2005; 35: 387-93.

[50] Luster T, Okagami L, Eds. Parenting: an ecological perspective. Hillsdale, NJ: Lawrence Erlbaum 1993.

[51] Lamborn SD, Mounts NS, Steinberg L, Dornbusch SM. Patterns of competence and adjustment among adolescents from authoritative, authoritarian, induigent, and neglectful families. Child Dev 1991; 62: 1049-65.

[52] Steinberg L, Lamborn SD, Dorbusch SM, Darling N. Impact of parenting practices on adolescent achievement: authoritative parenting, school involvement, and encouragement to succeed. Child Dev 1992; 63: 1266-81.

[53] Steinberg L, Lamborn SD, Darling N, Mounts NS, Dornbusch SM. Over-time changes in adjustment and competence among adolescents from authoritative, authoritarian, indulgent, and neglectful families. Child Dev 1994; 65: 754-70.

[54] Steinberg L, Blatt-Eisengart I, Cauffman E. Patterns of competence and adjustment among adolescents from authoritative, authoritarian, indulgent, and neglectful homes: A replication in a sample of serious juvenile offenders. J Res Adolesc 2006; 16: 4758.

[55] Martínez I, García JF. Internalization of values and self-esteem among Brazilian teenagers from authoritative, indulgent, authoritarian, and neglectful homes. Adolescence 2008; 43: 13-29.

[56] Lila M, García F, Gracia E. Perceived paternal and maternalacceptance and children's outcomes in Colombia. Soc Behav Pers 2007; 35: 115-24.

[57] Kitamura T, Sakamoto S, Yasumiya R, Sumiyama T, Fujihara S. Child abuse, other early experiences and depression: II. Single episode and recurrent/chronic subtypes of depression and their link to early experiences. Arch Women Ment Health 2000; 3: 53-8.

[58] Parker G, Kiloh L, Hayward L. Parental representations of neurotic and endogenous depressives. J Affect Disord 1987; 13: 75-82.

(C) Tanaka et al.; Licensee Bentham Open.

This is an open access article licensed under the terms of the Creative Commons Attribution Non-Commercial License (http://creativecommons.org/licenses/by-nc/3.0/) which permits unrestricted, non-commercial use, distribution and reproduction in any medium, provided the work is properly cited. 